\title{
A Model of the Semiannual Oscillation in the Equatorial Indian Ocean
}

\author{
Peter R. Gent and Kathleen O.'Neill
}

National Center for Atmospheric Research, ${ }^{1}$ Boulder, CO 80307

MARK A. CANE

Department of Earth, Atmospheric and Planetary Physics, Massachusetts Institute of Technology. Cambridge, MA 02139

(Manuscript received 25 April 1983, in final form 25 July 1983)

ABSTRACT

\begin{abstract}
Luyten and Roemmich have shown a strong semiannual signal in zonal velocity in the upper, western part of the equatorial Indian Ocean. Their observations are modeled by assuming that they are directly forced by the observed semiannual component of zonal wind stress, which is relatively large in the equatorial Indian Ocean. The model is linear, periodic, has linear damping, uses the long-wave approximation, and can be solved analytically. A good comparison with the observations is obtained for the phase of the oscillation across the array. The predicted magnitude is somewhat smaller than in the observations. The model sensitivity to friction and the spatial distribution of the wind stress is explored. Some additional model simplifications are discussed, but it is concluded that they all detract substantially from the comparison. The main conclusion is that the observations can be accounted for as a directly forced response to the semiannual component of the nearequatorial zonal winds.
\end{abstract}

\section{Introduction and model assumptions}

Luyten and Roemmich (1982) have analyzed current-meter observations that were taken in the western equatorial Indian Ocean from April 1979 to June 1980. The moorings were mainly on the equator between $50^{\circ} \mathrm{E}$ and $62^{\circ} \mathrm{E}$, at nominal depths of 200,500 , and $750 \mathrm{~m}$. By far the most energetic signal at all depths was a semiannual oscillation in the zonal velocity (see Luyten and Roemmich, Fig. 5, which is reproduced here as Fig. 1). The semiannual component in meridional velocity is small, containing only $1 / 40$ th of the energy in the zonal velocity, and the annual component in both velocities is small, and not well resolved by the observations. The oscillation has a magnitude of about $15 \mathrm{~cm} \mathrm{~s}^{-1}$, and has zonal and vertical scales that are very long compared to the dimensions of the array. The observations show upward phase, and hence, by analogy with vertically propagating equational waves, downward energy, propagation and, much less certainly, westward phase propagation (see Section 4). The basic premise of this paper is that this oscillation is forced by the basin-wide semiannual component of zonal wind stress $\tau^{x}$. This component of $\tau^{x}$ is strong in the central equatorial Indian Ocean where it dominates the annual component; for example, see McPhaden (1982, Fig. 2), who shows $\tau^{x}$ at Gan $\left(0^{\circ} 40^{\prime}\right.$, $73^{\circ} \mathrm{E}$ ).

\footnotetext{
'The National Center for Atmospheric Research is sponsored by the National Science Foundation.
}

With some caveats noted below, we take the dynamics to be linear. Since we are interested in the dominant semiannual signal, we consider the ocean response to be periodic at a single frequency, $\omega$. The driving is modeled as a body force in the mixed layer (see Lighthill, 1969). In fact, the surface layers of the ocean down through the thermocline are not linear: the currents there are strong, of the order of a meter per second. Philander and Pacanowski (1981) have analyzed periodic forcing in a multi-level primitive equation model. For semiannual period, they do indeed find differences below the thermocline depending upon whether the ocean is assumed to be linear or nonlinear (see their Fig. 4). An alternative, therefore, would be to postulate the forcing below the surface layer which drives the linear ocean beneath. It is not clear how best to do this; a nonlinear numerical model is probably necessary. Cane (1980) applied a three-layer numerical model to the Indian Ocean. With westerly winds, which predominate in the equatorial Indian Ocean, he found that nonlinearity near the surface drives the deeper ocean by downward advection of eastward momentum. The response to this advection is local in space and rapid in time, so that it would change the amplitude, but not the phase, of the deeper ocean response. The amplitude in our linear model is directly proportional to the magnitude of the wind-stress data of Hellerman and Rosenstein (1983), and this is not known very accurately anyway.

We force the model only by $\tau^{x}$ because the $\tau^{y}$ semiannual component is weaker, and, at this low fre- 


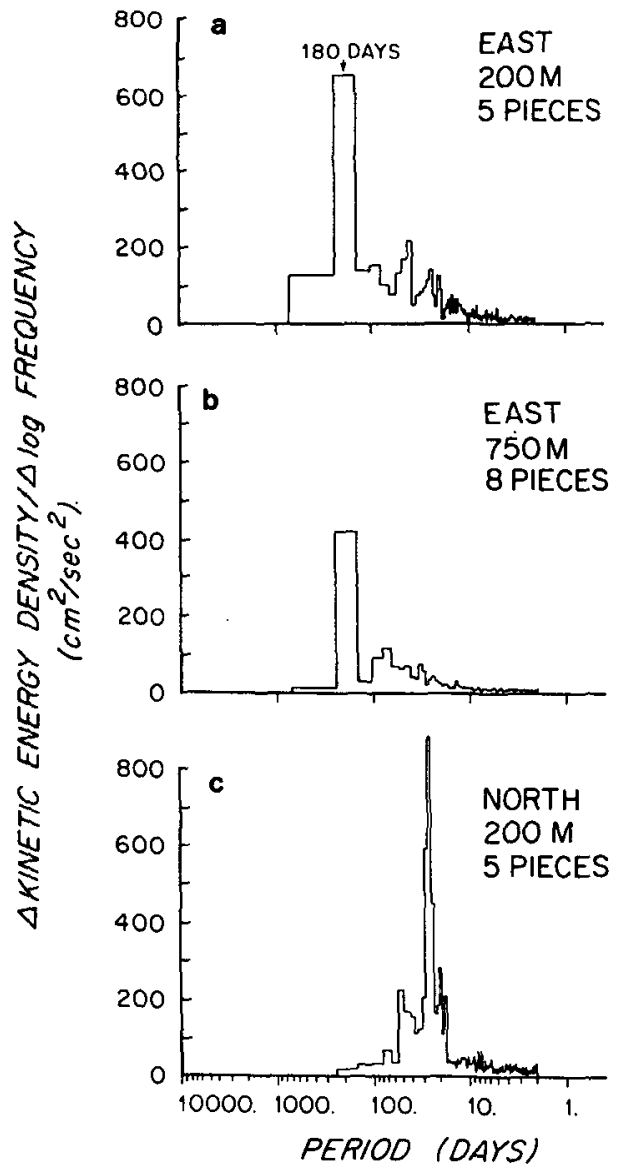

FIG. 1. Luyten and Roemmich (1982, Fig. 5) a) composite spectrum of $u$ at $200 \mathrm{~m}$, formed by averaging five records; b) as in a) except at $750 \mathrm{~m}$ and eight records; and c) as in a) except for $v$.

quency, is only $O(\omega)$ as effective as $\tau^{x}$ in driving the ocean. Another immediate consequence of small $\omega$ is that the meridional velocity is small, equal to $O(\omega)$ times the zonal velocity, in agreement with the observations of Luyten and Roemmich (1982). Our final major assumption is that damping in the model is caused by Rayleigh friction and Newtonian cooling of equal magnitude. This is convenient because it means the solution is still separable, and can be solved analytically as a sum of vertical modes. However, this assumption ignores coupling between the vertical modes. McCreary $(1981 \mathrm{a}, \mathrm{b})$ made a different assumption about damping, but with the same basic result that the solution is separable. Using a model similar to ours, and idealized buoyancy profiles and surface forcings, he has produced an undercurrent in the steady case and vertically propagating beams of energy in the periodic case. The present model is an extension of Cane and Sarachik's (1981) work which was applied to a single vertical mode. The extensions are to a three-dimensional solution by a sum over vertical modes, the inclusion of friction and cooling, and allowing the surface forcing to be spatially arbitrary rather than simple analytic functions of latitude alone.

\section{Model equations}

The linearized primitive equations on an equatorial $\beta$-plane, with the assumptions discussed in the last section are (see Moore and Philander, 1977):

$$
\begin{aligned}
& u_{t}-\beta y v+p_{x}=\exp (i \omega t) \tau_{z}^{x}(x, y, z)-r u \\
& v_{t}+\beta y u+p_{y}=-r v \\
& u_{x}+v_{y}+w_{z}=0 \\
& p_{z}=b \\
& b_{t}+N^{2} w=-r b
\end{aligned}
$$

where $p$ is pressure, $\omega$ the frequency, $r$ a damping coefficient with the dimension of frequency, $b$ the buoyancy and $N$ the buoyancy frequency defined by

$$
N^{2}=d \bar{b} / d z
$$

where $\bar{b}$ is the horizontally and time averaged buoyancy. Eqs. (1)-(5) can be separated by assuming vertical dependence such that

$$
u, v, p \propto F_{n}(z), \quad b \propto \frac{d F_{n}}{d z}, \quad w \propto \frac{d F_{n}}{d z} / N^{2} .
$$

The structure functions $F_{n}$, satisfy the equation

$$
\frac{d}{d z}\left(\frac{d F_{n}}{d z} N^{-2}\right)+F_{n} c_{n}{ }^{-2}=0
$$

where $c_{n}{ }^{2}$ is the separation constant, and the boundary conditions are

$$
\left.\begin{array}{c}
\frac{d F_{n}}{d z}+\frac{N^{2}}{g} F_{n}=0 \quad \text { at } \quad z=0 \\
\frac{d F_{n}}{d z}=0 \quad \text { at } \quad z=-H
\end{array}\right\} \text {. }
$$

We follow Lighthill (1969) and assume that the stress acts like a body force in a mixed layer of depth $d$ and not below, and define a projection coefficient $P_{n}$ such that

$$
P_{n}=\frac{H}{d} \int_{-d}^{0} F_{n} d z / \int_{-H}^{0} F_{n}{ }^{2} d z
$$

The equations are nondimensionalized in the usual equatorial way with velocities $\propto c_{n}$, lengths $\propto\left(c_{n}\right)$ $\beta)^{1 / 2}$, frequency $\propto\left(c_{n} \beta\right)^{1 / 2}$ and pressure $\propto c_{n}^{2}$. Then, in the long-wave approximation, where $\omega$ and zonal derivatives are assumed to be small, Eqs. (1)-(5) for the $n$th vertical mode reduce to (see Cane and Sarachik, 1981)

$$
\begin{gathered}
u_{t}-y v+p_{x}=P_{n} \exp \left(i \omega_{n} t\right) \tau^{x}(x, y)-r_{n} u, \\
y u+p_{y}=0, \\
p_{t}+u_{x}+v_{y}=-r_{n} p .
\end{gathered}
$$


$\tau^{x}$ is now the surface stress, $r_{n}$ equals $r\left(c_{n} \beta\right)^{-1 / 2}$, and the long-wave approximation means the zonal flow is geostrophically balanced everywhere. The solution of (11)-(13) is given by Cane and Sarachik (1981) with the damping terms accommodated by replacing $\omega_{n}$ by

$$
\bar{\omega}_{n} \equiv \omega_{n}-i r_{n}
$$

everywhere it occurs except in the time dependent term. The solution does not include the short Rossby waves that propagate eastwards from the western boundary. These waves have very small group velocity and would be dissipated by friction before they penetrate into the interior. The solution also ignores the Rossby waves that are trapped to the eastern boundary. These waves form the poleward traveling coastal Kelvin waves at large distances from the equator, and thus the solution is not valid for large $|y|$. This becomes important for the higher-order Rossby waves polewards of about $10^{\circ}$, but they have smaller amplitude and are more heavily damped than the graver Rossby waves. The number of long propagating Rossby waves for each vertical mode is calculated from the exact equatorial dispersion relation, but then those retained are all assumed to be nondispersive with group and phase velocities given by $-(2 m+1)^{-1}$. The solution and details of its calculation are given in the appendix.

If the damping coefficient $r$ is taken to be of Rayleigh type, i.e., a constant in Eqs. (1)-(5), then, because it has the dimension of frequency,

$$
r_{n} \propto c_{n}^{-q},
$$

with $q=0.5$. This form of friction is convenient because it allows vertical separation. McCreary (1981a) achieved the same end by assuming the vertical damping to be proportional to

$$
\frac{d}{d z}\left(N^{-2} \frac{d}{d z}\right) \propto c_{n}^{-2}
$$

from the vertical structure function [Eq. (8)]. Thus in McCreary's work $q=2.5$ in Eq. (15). Alternatively, the linear damping can be thought of as an approximation to horizontal Laplacian damping. The horizontal length scale is proportional to $c_{n}{ }^{1 / 2}$, so that this interpretation gives $q=1.5$. Approximating a biharmonic horizontal friction in the same way would again give $q=2.5$. In the absence of any justification for one value of $q$ over any other, we have run cases for $q=0.0,0.5,1,1.5,2$ and 2.5 , and called $q=1.5$ the standard case mainly on the basis of it being in the middle of the values used. In sequences of runs using different values of $q$, we have used the same value of friction for the first vertical mode, and then higher modes are successively more heavily damped as $q$ increases. The magnitude of the friction on the first mode is governed by the spindown time chosen for $r$. We have used spindown times of one, two and three years, with the two-year spindown time being the standard case. Assuming vertical and horizontal length scales of $100 \mathrm{~m}$ and $300 \mathrm{~km}$ respectively, a two-year spindown time gives vertical and horizontal eddy viscosities of $1.6 \mathrm{~cm}^{2} \mathrm{~s}^{-1}$ and $1.4 \times 10^{7} \mathrm{~cm}^{2} \mathrm{~s}^{-1}$, respectively: reasonable values for the equatorial ocean and certainly in the same range as those used in large numerical models.

\section{Results using Hellerman and Rosenstein's wind stress}

The model was forced using the semiannual component of $\tau^{x}$ calculated from the monthly wind-stress data set of Hellerman and Rosenstein (1983). The data set is averaged for every month and for every $2^{\circ}$ of latitude and longitude. We extracted the semiannual component of $\tau^{x}$ and confirmed that this is considerably larger than the annual component in the center of the Indian Ocean. The magnitude of the semiannual component along the equator is shown in Fig. 2. It shows that the component is large over the central third of the Indian Ocean and has a secondary maximum near the coast of Africa. The spatial distribution of the semi-annual component of $\tau^{x}$ over the tropical Indian Ocean is shown in Fig. 3 in terms of amplitude and phase relative to 1 January. The dominant feature is in the Arabian Sea where the maximum amplitude is $0.84 \mathrm{dyn} \mathrm{cm}^{-2}$. The annual component of $\tau^{x}$ is of the same order of magnitude there, and both are due to the very strong winds of the monsoon circulation in the Arabian Sea. The two components are about equal there because the wind is strong southwesterly for about four months of the year rather than the six required for the annual component to dominate. However, this dominant feature has only a small effect on the results along the equator (see Section 5). The phase diagram indicates that the semiannual component is a maximum on the equator first in late April

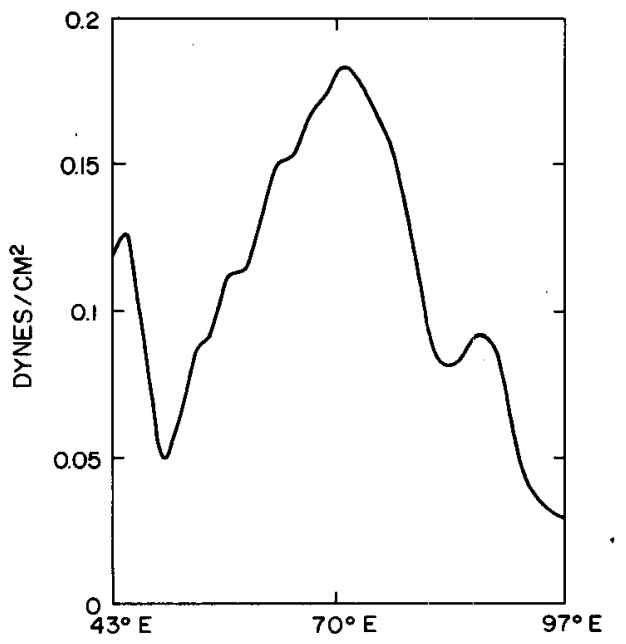

FiG. 2. The average of Hellerman and Rosenstein's semiannual components of $\tau^{x}$ at $1^{\circ} \mathrm{N}$ and $1^{\circ} \mathrm{S}$ across the Indian Ocean. 
a) AMPLITUDE

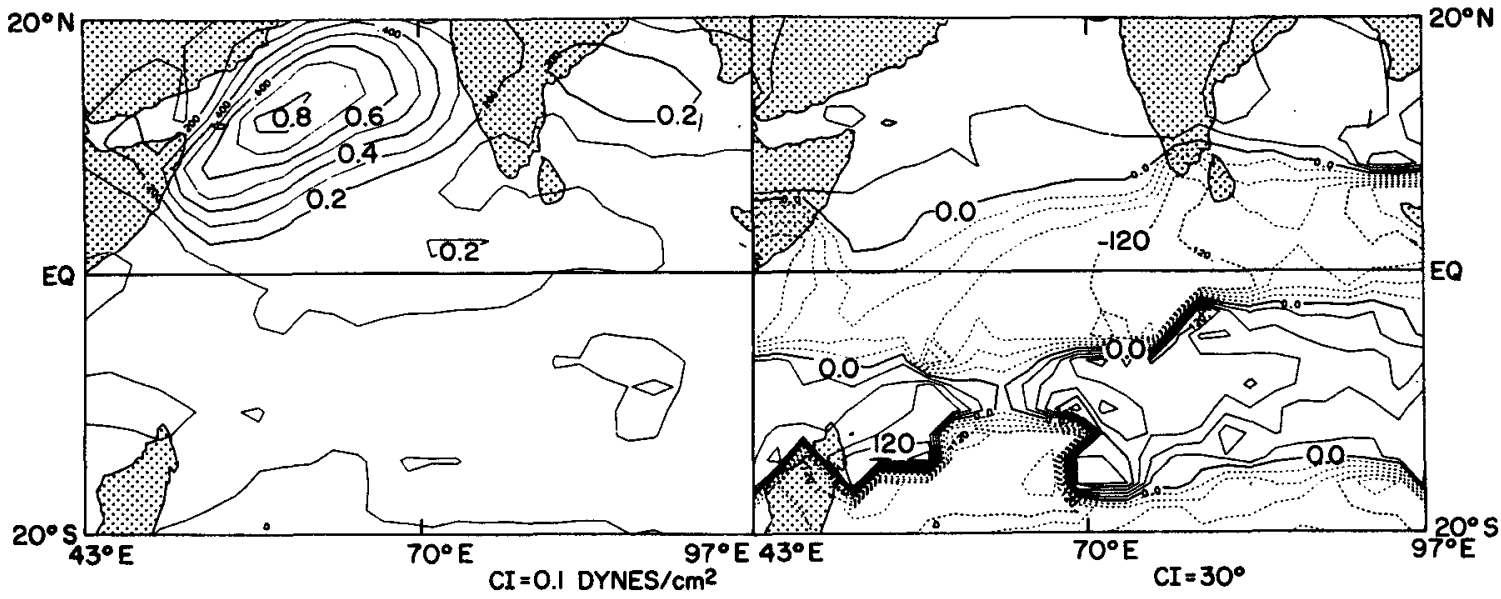

FIG. 3. Spatial distribution of a) amplitude and b) phase of the semiannual component of $\tau^{x}$ from Hellerman and Rosenstein's data between $43^{\circ} \mathrm{E}$ and $97^{\circ} \mathrm{E}$ and $20^{\circ} \mathrm{N}$ to $20^{\circ} \mathrm{S}$. The amplitude unit is dyn $\mathrm{cm}^{-2}$. The phases are calculated relative to $1 \mathrm{January}$ by assuming that the monthly averages apply at the middle of each month.

at about $81^{\circ} \mathrm{E}$. The maximum travels westward, and reaches $53^{\circ} \mathrm{E}$ about seven weeks later. Note that our phase convention is that propagation is indicated by increasing values of phase. The maximum on the African coast propagates northeastward, occurring earlier at the equator than farther north.

We interpolated Hellerman and Rosenstein's data to our resolution, which is $1^{\circ}$ in latitude and longitude, and now describe the solution with $q=1.5$ and a spindown time of two years. These are our standard parameters because they give the best comparison with the observations. A buoyancy profile was calculated using all CTD data taken along $53^{\circ} \mathrm{E}$ between $5^{\circ} \mathrm{N}$ and $0.75^{\circ} \mathrm{S}$ during May and June of 1976. It has a resolution of $25 \mathrm{~m}$ over the whole depth of the ocean, which is taken to be $5 \mathrm{~km}$. Details are given by O'Neill
(1982). In this model, $N$ is used as if it is the time and space average of the buoyancy profile in the whole of the equatorial Indian Ocean. We took the average mixed-layer depth to be $50 \mathrm{~m}$ because this is the value at Gan as calculated by McPhaden (1982). We then set the buoyancy profile to zero over the depth of this idealized mixed layer, where the stress is assumed to act as a body force. The upper $1 \mathrm{~km}$ of the buoyancy profile $N$ used to calculate the vertical modes is shown in Fig. 4, and has a maximum of 13.5 cycles per hour (cph) at about $90 \mathrm{~m}$. The upper kilometer of the first five vertical modes, multiplied by their respective projection coefficients $P_{n}$, is also shown in Fig. 4. The second vertical mode is excited most strongly and is dominant at the surface in our solutions. This mode is zero just above $200 \mathrm{~m}$, and has a subsurface max-

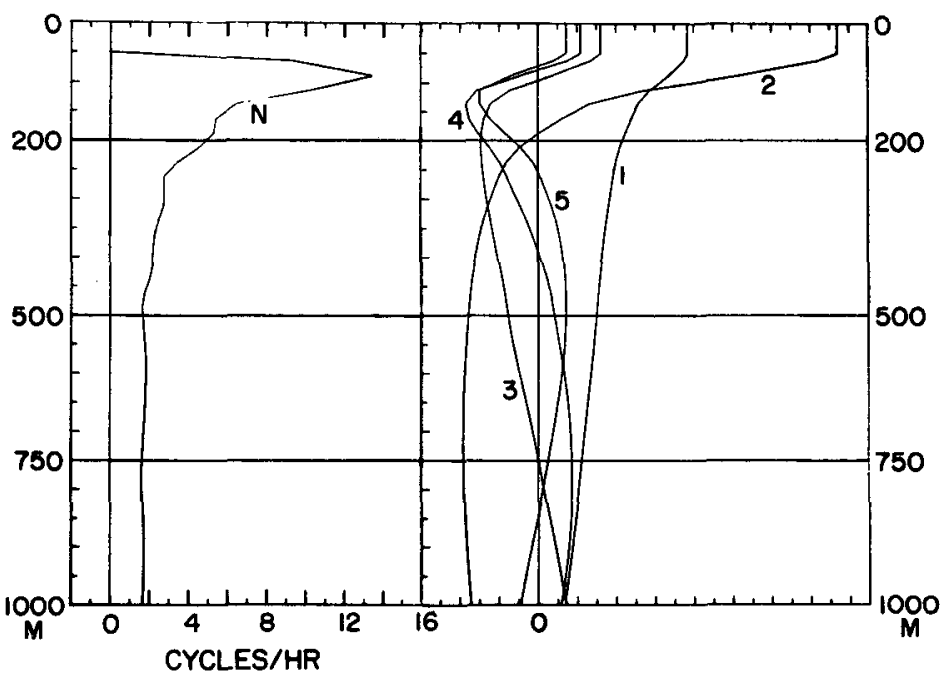

FiG. 4. Profiles of the model buoyancy frequency $N$ and the first five vertical modes multiplied by their projection coefficients $P_{n}$, over the upper $1 \mathrm{~km}$. 
imum between 600 and $850 \mathrm{~m}$. At $750 \mathrm{~m}$, there is almost no contribution from the third mode. We have taken $\bar{n}$ to be 14 in Eq. (A20) because the higher projection coefficients are less than $1 \%$ of the largest, which is $P_{2}$. Details of the vertical modes are given in Table 1 .

Horizontal sections of the amplitude of the spatially varying components of $u, v$ and geopotential height $(h \equiv p / g)$ at $750 \mathrm{~m}$ are shown in Fig. 5. The second vertical mode dominates at this depth and the most obvious feature in Fig. 5 is the Rossby wave focus for this mode which occurs almost in the center of the ocean where $\omega\left(X_{E}-x\right) / c_{2}=\pi / 4$ (Schopf et al. 1981; Cane and Moore 1981). The solution is meridionally confined in the western half of the basin, but gradually increases in width toward the eastern boundary where it is meridionally unconfined because the height field is constant along that boundary in the long-wave approximation. This characteristic of the solution is independent of depth, but the dominance of the secondmode focus is not. This can be seen from Fig. 6, which shows the amplitude of $u$ at $500 \mathrm{~m}$ and $u$ and $h$ at $200 \mathrm{~m}$; these are the other depths of the observations. At $500 \mathrm{~m}$ no single mode dominates, but the focus of the second mode can be seen near the center of the ocean at about $67^{\circ} \mathrm{E}$. The second vertical mode is almost zero at $200 \mathrm{~m}$. At this depth the focus for the third mode can clearly be seen at about $80^{\circ} \mathrm{E}$, and there are hints of a first mode focus near the western boundary. The locations of these foci are again accounted for by the theory of Schopf et al. (1981).

The height field at $200 \mathrm{~m}$ shows signs of a relative maximum under the dominant feature in the Arabian Sea. This maximum becomes more evident above 200 $\mathrm{m}$, and is very clear in the surface-height field. The surface in our model is dominated by the second vertical mode (see Fig. 4), and the maximum zonal velocity

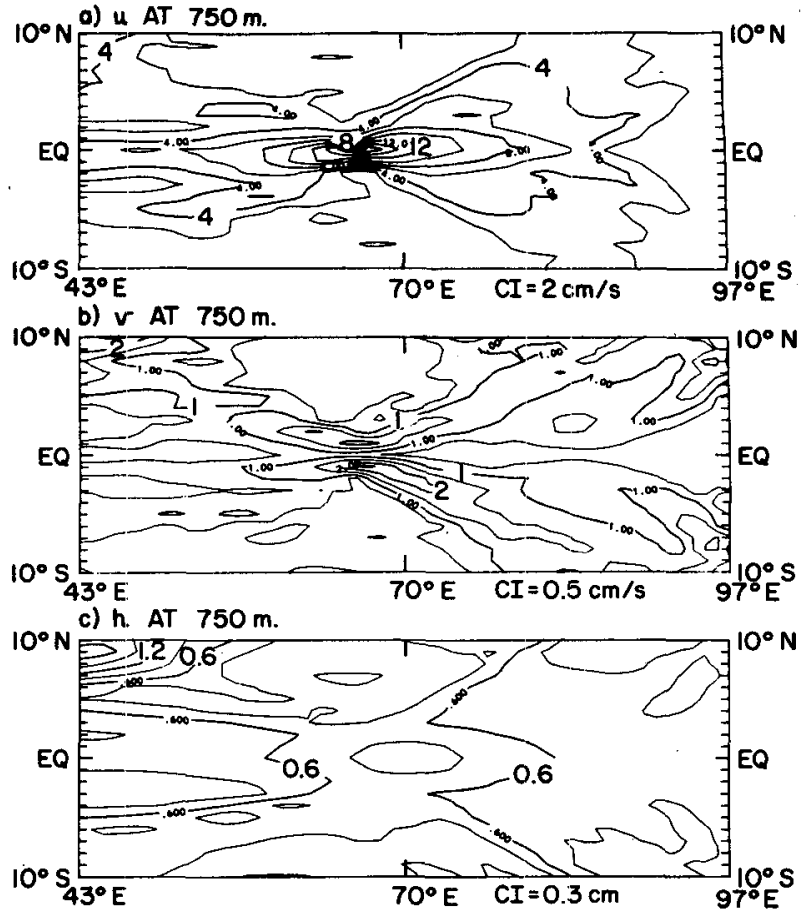

FIG. 5. Horizontal sections of the amplitude of the spatially varying component of a) $u$, b) $v$ and c) $h$ between $10^{\circ} \mathrm{N}$ and $\mathrm{S}$ at a depth of $750 \mathrm{~m} . u$ and $v$ are in $\mathrm{cm} \mathrm{s}^{-1}, h$ is in $\mathrm{cm}$ and the contour interval (CI) is listed below each plot.

at the focus is $\sim 80 \mathrm{~cm} \mathrm{~s}^{-1}$. Nonlinearity is important in the surface layer, as discussed in the introduction, and would act to reduce the magnitude of this maximum. We note, however, that this surface maximum in $u$ occurs at the correct time and longitude of the observed surface jet described by Wyrtki (1973). Our model is unrealistic in the surface layer, so it is excluded from the vertical sections of velocity in subsequent

TABLE 1. Details of the vertical structure and friction of the model.

\begin{tabular}{|c|c|c|c|c|c|c|c|c|}
\hline \multirow{2}{*}{$\begin{array}{c}\text { Mode } \\
\text { number }\end{array}$} & \multirow{2}{*}{$\begin{array}{l}\text { Equivalent } \\
\text { depth } \\
\text { (cm) }\end{array}$} & \multirow{2}{*}{$\begin{array}{c}\text { Kelvin } \\
\text { wave speed } \\
\left(\mathrm{cm} \mathrm{s}^{-1}\right)\end{array}$} & \multirow{2}{*}{$\begin{array}{c}\text { Length scale } \\
(\mathrm{km})\end{array}$} & \multirow{2}{*}{$\begin{array}{c}\text { Time scale } \\
\text { (days) }\end{array}$} & \multirow{2}{*}{$\begin{array}{c}\text { Number of } \\
\text { propagating } \\
\text { Rossby } \\
\text { waves }\end{array}$} & \multirow{2}{*}{$\begin{array}{l}\text { Projection } \\
\text { coefficient } \\
P_{n}\end{array}$} & \multicolumn{2}{|c|}{$\begin{array}{c}\text { Values of } r_{n} / \omega_{n} \text { using } \\
\text { two-year spindown } \\
\text { time* }\end{array}$} \\
\hline & & & & & & & $q=1.5$ & $q=2.5$ \\
\hline 1 & 79.9 & 280 & 349 & 1.4 & 49 & 3.9 & 0.04 & 0.04 \\
\hline 2 & 30.5 & 173 & 275 & 1.8 & 30 & 5.5 & 0.06 & 0.10 \\
\hline 3 & 12.6 & 111 & 220 & 2.3 & 19 & 2.5 & 0.10 & 0.25 \\
\hline 4 & 6.5 & 80 & 187 & 2.7 & 13 & 2.1 & 0.14 & 0.49 \\
\hline 5 & 4.4 & 66 & 170 & 3.0 & 11 & 1.7 & 0.17 & 0.72 \\
\hline 6 & 2.9 & 53 & 153 & 3.3 & 9 & 1.4 & 0.21 & 1.09 \\
\hline 7 & 2.1 & 46 & 141 & 3.6 & 7 & 1.3 & 0.24 & 1.49 \\
\hline 8 & 1.6 & 40 & 132 & 3.8 & 6 & 1.5 & 0.28 & 1.98 \\
\hline 9 & 1.3 & 35 & 124 & 4.1 & 5 & 1.4 & 0.31 & 2.48 \\
\hline 10 & 1.1 & 32 & 119 & 4.3 & 5 & 1.3 & 0.34 & 2.98 \\
\hline 11 & 0.9 & 29 & 113 & 4.5 & 4 & 1.8 & 0.38 & 3.67 \\
\hline 12 & 0.8 & 28 & 111 & 4.6 & 4 & 1.4 & 0.40 & 3.95 \\
\hline 13 & 0.7 & 26 & 106 & 4.8 & 4 & 0.3 & 0.43 & 4.75 \\
\hline 14 & 0.6 & 24 & 102 & 5.0 & 3 & 0.1 & 0.47 & 5.57 \\
\hline
\end{tabular}

* When $q=0.5, r_{n} / \omega_{n}$ is 0.04 for all the vertical modes. 

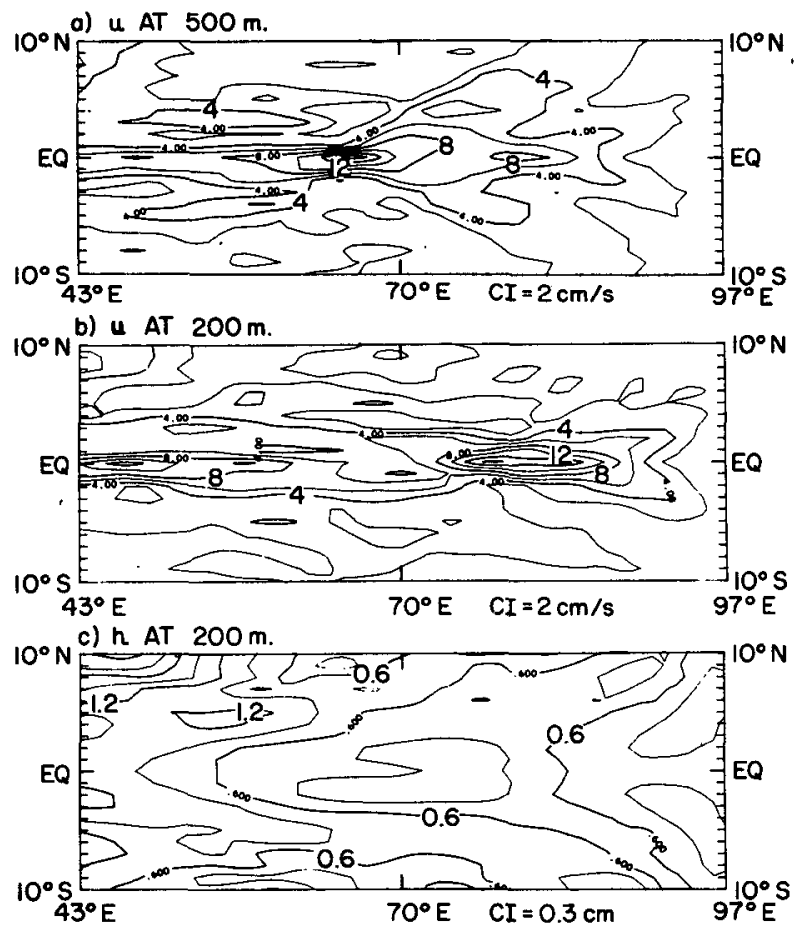

FiG. 6. Horizontal sections of the amplitude of a) $u$ at $500 \mathrm{~m}$, b) $u$ at $200 \mathrm{~m}$ and c) $h$ at $200 \mathrm{~m}$ between $10^{\circ} \mathrm{N}$ and $10^{\circ} \mathrm{S}$. The units are $\mathrm{cm} \mathrm{s}^{-1}$ and $\mathrm{cm}$.

figures. On the other hand, vertically integrated quantities such as dynamic topography are not strongly affected by nonlinearity. The surface geopotential height relative to $500 \mathrm{~m}$ at $49^{\circ} \mathrm{E}$ has an amplitude of $4.4 \mathrm{~cm}$, which is only slightly smaller than the observed semiannual component there taken from vertical profiles analyzed by Bruce (1981, Fig. 12).
Figure 7 shows the amplitude and phase of $u$ in a section along the equator and from a depth of $150 \mathrm{~m}$ to the bottom at $5 \mathrm{~km}$. The amplitude maximum at depth is at the longitude of the focus for the second vertical mode and is at about $800 \mathrm{~m}$ which is the depth of the subsurface maximum of this mode (see Fig. 4). The phase diagram shows upward phase propagation in the upper and western part of the basin with westward phase propagation in the west. The phase is much more complicated in the eastern third of the basin with no overall propagation characteristics. Fig. 8 shows profiles of $u$ at both ends of the array $\left(50^{\circ} \mathrm{E}\right.$ and $\left.62^{\circ} \mathrm{E}\right)$ at times $\omega t=0,45^{\circ}, 90^{\circ}, 135^{\circ}$ and $180^{\circ}$, from 150 $\mathrm{m}$ to the ocean bottom. Both show broad jets that migrate vertically during the oscillation cycle. There is very little structure in the deep ocean.

\section{Comparison with the observations}

In order to compare our results with those of Luyten and Roemmich (1982), we show in Fig. 9 the upper western half of the ocean from Fig. 7 . It shows the amplitude and phase of $u$ along the equator between 43 and $70^{\circ} \mathrm{E}$ and between 150 and $850 \mathrm{~m}$. The instrument locations are marked in Fig. 9 with a cross: note that all three at $62^{\circ} \mathrm{E}$ are $50 \mathrm{~m}$ higher than at the other longitudes. The amplitude and phase of $u$ from the observations (Luyten and Roemmich, Table 1) and from our model are listed in Table 2 . The observational uncertainty in amplitude is fairly small, and Luyten and Roemmich estimate the uncertainty in any phase difference to be $20^{\circ}$.

The model amplitudes are somewhat smaller than those observed (see Table 2). The second vertical mode, which dominates at most other depths, is zero just above $200 \mathrm{~m}$ (see Fig. 4) so that the model amplitudes

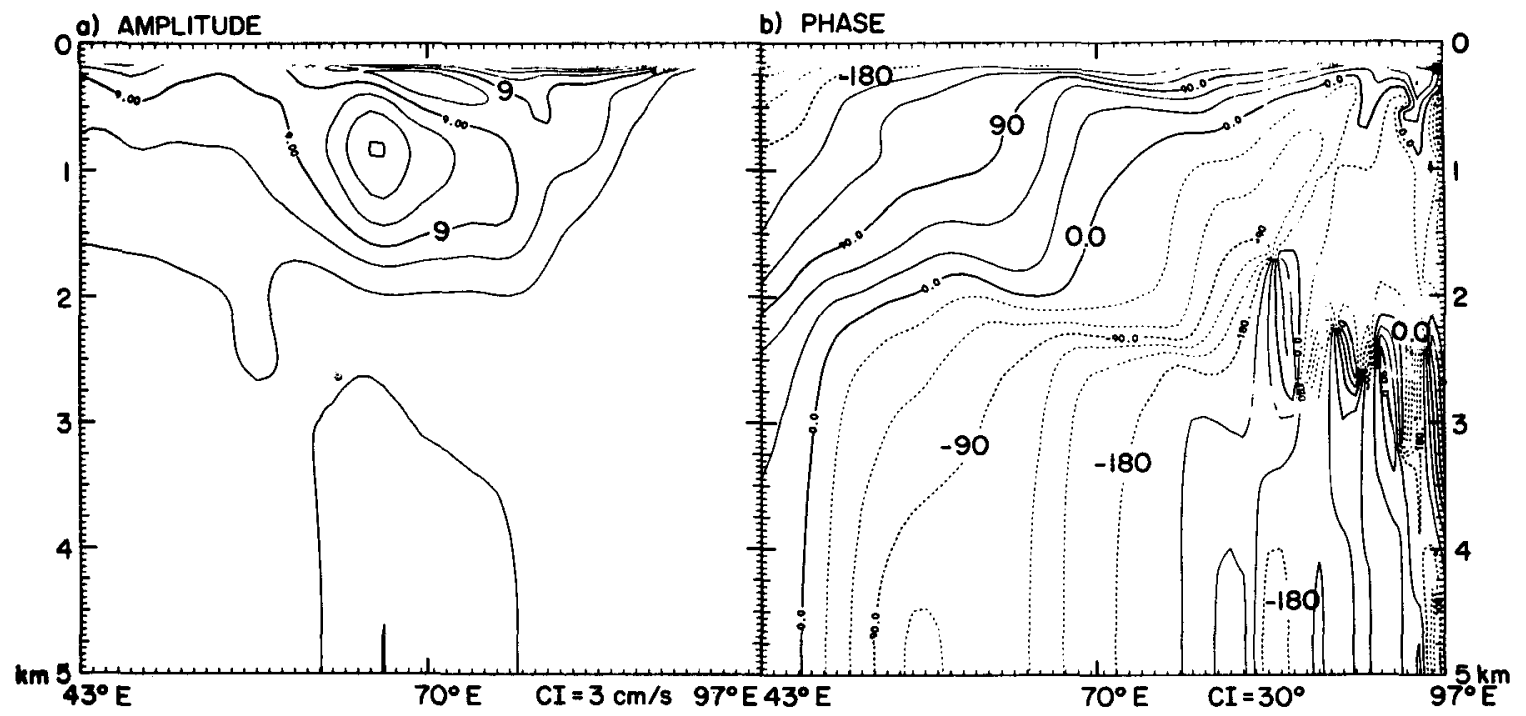

FIG. 7. Vertical section of a) amplitude and b) phase of $u$ along the equator between $150 \mathrm{~m}$ and $5 \mathrm{~km}$. The amplitude unit is $\mathrm{cm} \mathrm{s}^{-1}$. 


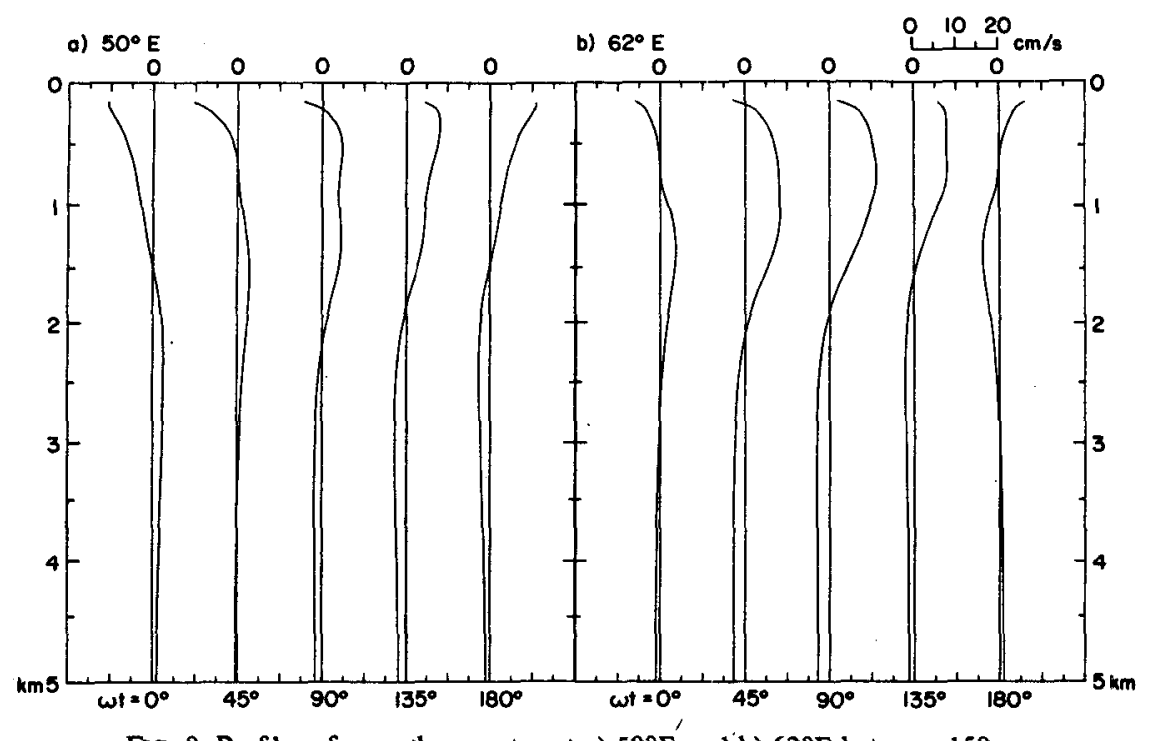

FIG. 8. Profiles of $u$ on the equator at a) $50^{\circ} \mathrm{E}$ and b) $62^{\circ} \mathrm{E}$ between $150 \mathrm{~m}$ and $5 \mathrm{~km}$ at times $\omega t=0,45^{\circ}, 90^{\circ}, 135^{\circ}$ and $180^{\circ}$. The unit is $\mathrm{cm} \mathrm{s}^{-1}$.

are small at this depth, but see Section 5a. Reducing friction on the higher modes by decreasing the value of $q$ has the counter-intuitive result of reducing the amplitudes at $750 \mathrm{~m}$ at the array longitudes, although overall the amplitude of the oscillation in the deep ocean is increased. The low model amplitudes could be caused by the assumption of linear surface dynamics as discussed in the introduction. We also note that we are comparing a climatological average solution with observations from one particular year.

The model phases given in Table 2 reproduce those of the observations much better, although the fact that the second mode is zero close to $200 \mathrm{~m}$ means that the model phases there are strong functions of depth: phase changes of nearly $40^{\circ}$ can be seen over $50 \mathrm{~m}$ near $65^{\circ} \mathrm{E}$ (see Fig. 9). The model shows upward phase, and hence by analogy downward energy, propagation at all array longitudes, as do the observations. The model also has westward propagation at all array points at all depths. Luyten and Roemmich deduced overall westward propagation from the observations, but it is not consistent between all instruments at 200 and 750 $\mathrm{m}$. They calculated an average phase difference between 200 and $750 \mathrm{~m}$ as $70^{\circ}$, whereas the model has $61^{\circ}$. The average phase difference across the array at 500 and $750 \mathrm{~m}$ is $22^{\circ}$ in the observations as compared to $39^{\circ}$ in the model. The absolute magnitudes of the model phases are also close to those of the observations. An average over all array points shows that the observations lead the model by $5^{\circ}$ or 2.5 days on average, which is much smaller than the time resolution of the data. Individual phase differences are much larger, however, up to $47^{\circ}$.

\section{Model sensitivities \\ a. $N$ and the depth of the mixed layer}

The vertical-structure functions depend upon the buoyancy profile $N$, and it is known that they can

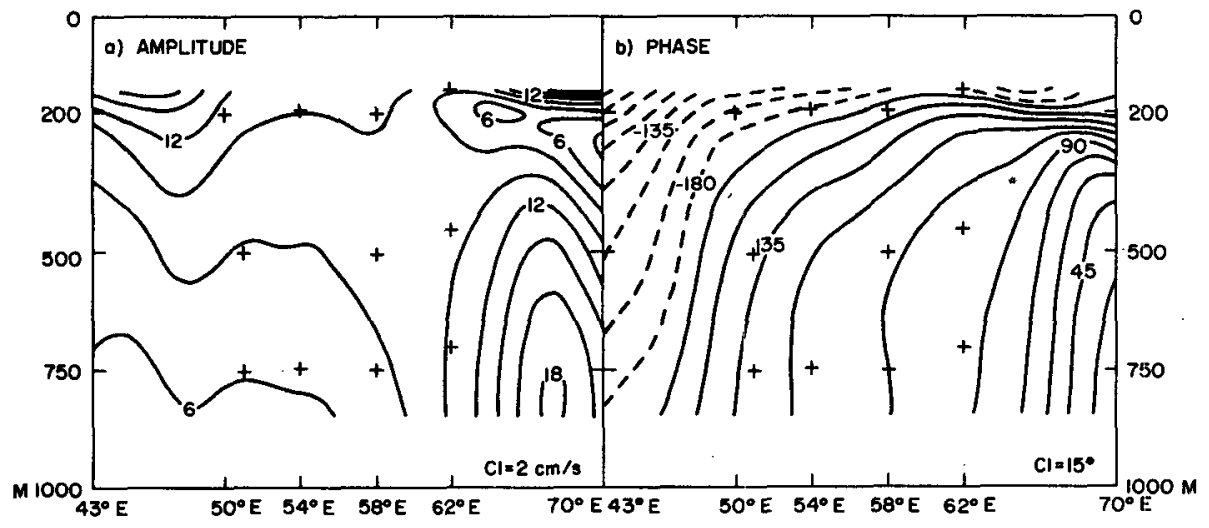

FIG. 9. Vertical section of a) amplitude and b) phase of $u$ along the equator between 43 and $70^{\circ} \mathrm{E}$ and 150 to $850 \mathrm{~m}$. The amplitude unit is $\mathrm{cm} \mathrm{s}^{-1}$. 
TABLE 2. Amplitude ( $\mathrm{cm} \mathrm{s}^{-1}$ ) and phase of $u$ at four longitudes on the equator. The phases are relative to 1 January.

\begin{tabular}{lcccc}
\hline \hline $\begin{array}{c}\text { Nominal } \\
\text { depth }\end{array}$ & $\begin{array}{c}50^{\circ} \text { or } \\
51^{\circ} \mathrm{E}\end{array}$ & $54^{\circ} \mathrm{E}$ & $58^{\circ} \mathrm{E}$ & $62^{\circ} \mathrm{E}$ \\
\hline \multicolumn{5}{c}{ Observations } \\
$200 \mathrm{~m}$ & $15\left(161^{\circ}\right)$ & $18\left(170^{\circ}\right)$ & $17\left(194^{\circ}\right)$ & $14\left(164^{\circ}\right)$ \\
$500 \mathrm{~m}$ & $10\left(142^{\circ}\right)$ & - & $15\left(136^{\circ}\right)$ & $18\left(122^{\circ}\right)$ \\
$750 \mathrm{~m}$ & $14\left(115^{\circ}\right)$ & $14\left(97^{\circ}\right)$ & $14\left(107^{\circ}\right)$ & $9\left(92^{\circ}\right)$ \\
& & & & \\
& & Model $^{*}$ & & \\
$200 \mathrm{~m}$ & $10.8\left(187^{\circ}\right)$ & $9.9\left(174^{\circ}\right)$ & $10.0\left(147^{\circ}\right)$ & $6.9\left(170^{\circ}\right)$ \\
$500 \mathrm{~m}$ & $7.8\left(136^{\circ}\right)$ & $7.9\left(119^{\circ}\right)$ & $8.8\left(106^{\circ}\right)$ & $10.0\left(96^{\circ}\right)$ \\
$750 \mathrm{~m}$ & $6.0\left(128^{\circ}\right)$ & $6.3\left(113^{\circ}\right)$ & $7.8\left(103^{\circ}\right)$ & $11.2\left(91^{\circ}\right)$ \\
\hline
\end{tabular}

${ }^{*} q=1.5$ and spindown time of two years.

change substantially in the surface layer due to small changes in $N$. In our model the second mode has a zero very close to $200 \mathrm{~m}$, so that we do not consider the relatively small magnitudes at $200 \mathrm{~m}$ in Table 2 as a major discrepancy.

Changing the depth of the mixed layer has two separate effects. First, we set the buoyancy profile to zero down to depth $d$, which changes the vertical modes. These changes are moderate if $d \leqslant 75 \mathrm{~m}$, but large if $d$ is $100 \mathrm{~m}$ because the maximum in the observed $N$ is at about $90 \mathrm{~m}$ (see Fig. 4). Second, it alters the projection coefficients, and again the changes are only moderate for $d \leqslant 75 \mathrm{~m}$, but larger if $d=100 \mathrm{~m}$. This can be seen from Table 3 which lists $P_{n}$ for the first five modes when $d$ takes the values 50,75 , and $100 \mathrm{~m}$.

\section{b. Friction}

Friction is necessary in the model because it does act in the ocean, and is required to control the nearsingularity that would occur in $u$ in the inviscid case (see Cane and Moore, 1981). It is not clear how best to model friction, so we vary our assumed form considerably in this section to assess model sensitivity.

We have run the Hellerman and Rosenstein semiannual $\tau^{x}$ forcing with a spindown time of two years with $q=0-2.5$ in steps of 0.5 and for spindown times of one and three years with $q=1.5$. Certain properties

TABLE 3. Projection coefficients $P_{n}$ for various mixed layer depths.

\begin{tabular}{cccc}
\hline \hline & \multicolumn{3}{c}{$\begin{array}{c}\text { Depth of mixed layer } \\
(\mathrm{m})\end{array}$} \\
\cline { 2 - 4 } Mode number & 50 & 75 & 100 \\
\hline & 3.9 & 3.7 & 3.2 \\
2 & 5.5 & 5.2 & 4.4 \\
3 & 2.5 & 2.4 & 2.4 \\
4 & 2.1 & 1.7 & 1.5 \\
5 & 1.7 & 1.4 & 1.5 \\
\hline
\end{tabular}

of the phases from these model runs are given in Table 4. The table shows that when friction is weak (either $q \leqslant 1$ for a spindown time of two years, or a spindown time of three years), upward phase propagation does not occur at all array longitudes. When $q \leqslant 1$ westward phase propagation does not occur at all array points at 500 and $750 \mathrm{~m}$. These properties do occur when the friction is stronger and in the observations. Increasing friction tends to produce a larger phase difference between 200 and $750 \mathrm{~m}$, but also increases the horizontal phase difference across the array at 500 and $750 \mathrm{~m}$. The vertical phase properties noted above are consistent with the fact that, when friction is weak, more energy reflects from the ocean bottom than when it is strong, so that upward energy propagation at any point is more likely in the former case than in the latter.

Table 4 shows that phase properties in the array are sensitive to the form of friction. Certain features of the solution are very sensitive to friction. The magnitude of the subsurface maximum of the focus for the second mode is a good example. This can be seen from Fig. 10, which is a plot of the amplitude of $u$ along the equator between $150 \mathrm{~m}$ and $2.5 \mathrm{~km}$ for $q=0.5$ and 2.5 with a spindown time of two years, and for spindown times of one and three years when $q=1.5$. The same plot for the standard case is shown in Fig. 7. The magnitude of the maximum varies between 11.0 and $26.6 \mathrm{~cm} \mathrm{~s}^{-1}$. In summary, although many aspects of the solution are very sensitive to friction, the results in the array area are only sensitive as long as $r_{n} / \omega_{n}$ for the dominant modes is not order one or larger.

TABLE 4. Sensitivity to friction and $\tau^{x}$.

\begin{tabular}{|c|c|c|c|}
\hline & & $\begin{array}{c}\text { Upward phase } \\
\text { propagation at } \\
\text { all array } \\
\text { longitudes? }\end{array}$ & $\begin{array}{c}\text { Does phase } \\
\text { always increase } \\
\text { to the west at } \\
500 \text { and } 750 \mathrm{~m} \text { ? }\end{array}$ \\
\hline \multirow{2}{*}{\multicolumn{2}{|c|}{$\begin{array}{c}\text { Spindown time } \\
\text { (years) }\end{array}$}} & \multicolumn{2}{|c|}{$\begin{array}{l}\text { Hellerman and Rosenstein } \\
\text { wind stress }\end{array}$} \\
\hline & & & \\
\hline 0.0 & 2 & No & No \\
\hline 0.5 & 2 & No & No \\
\hline 1.0 & 2 & No & No \\
\hline 1.5 & 2 & Yes & Yes \\
\hline 2.0 & 2 & Yes & Yes \\
\hline 2.5 & 2 & Yes & Yes \\
\hline 1.5 & 1 & Yes & Yes \\
\hline 1.5 & 3 & No & Yes \\
\hline \multicolumn{4}{|c|}{$\begin{array}{c}\tau^{x}=0.25 \exp \left[-(y / L)^{2}\right] \text { dyn } \mathrm{cm}^{-2} \\
L=750 \mathrm{~km}\end{array}$} \\
\hline \multicolumn{4}{|c|}{ Zonal extent } \\
\hline \multirow{3}{*}{\multicolumn{2}{|c|}{$\begin{array}{l}\text { All basin } \\
\text { Western half } \\
\text { Eastern half }\end{array}$}} & No & Yes \\
\hline & & No & No \\
\hline & & Yes & Yes \\
\hline
\end{tabular}



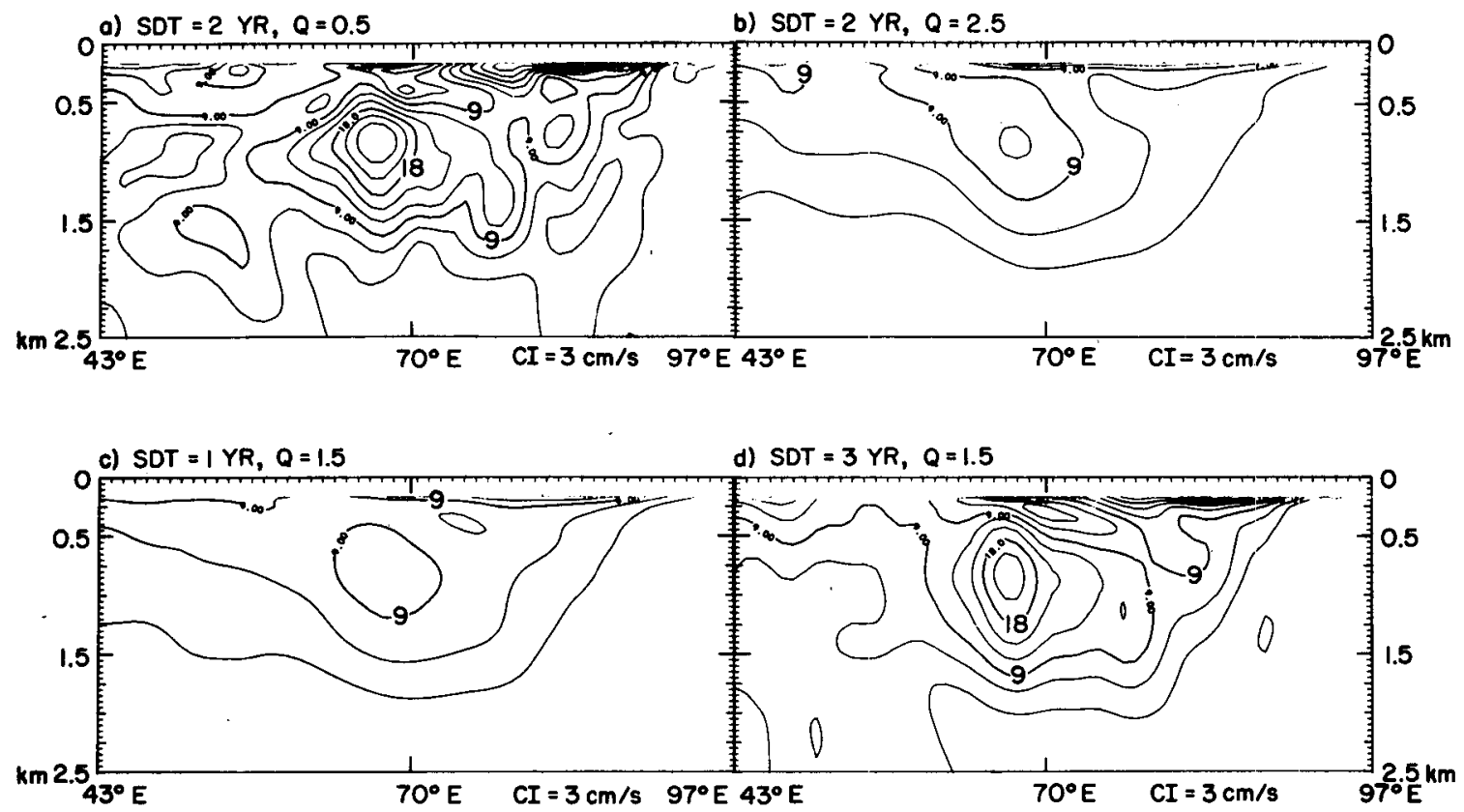

Fig. 10. Vertical section of the amplitude of $u$ along the equator between $150 \mathrm{~m}$ and $2.5 \mathrm{~km}$ a) for $q=0.5$ and b) for $q=2.5$ with a spindown time of two years; and spindown times of c) one year and d) three years when $q$ $=1.5$. The unit is $\mathrm{cm} \mathrm{s}^{-1}$.

\section{c. $\tau^{x}$ as a function of $y$}

We tested the model sensitivity to $\tau^{x}$ as a function of $y$ in two ways. First, we simulated the Arabian Sea feature of Hellerman and Rosenstein's data shown in Fig. 3 whose maximum is over four times the maximum found along the equator. We ran two cases both of which were forced only by "Gaussian hills" in $\tau^{x}$ of magnitude $0.8 \mathrm{dyn}^{-2}$ centered at $12^{\circ} \mathrm{N}, 60^{\circ} \mathrm{E}$. The first had an $e$-folding scale of $550 \mathrm{~km}$, which means that the stress is essentially zero south of $4^{\circ} \mathrm{N}$, and the second a scale of $880 \mathrm{~km}$, which means that $\tau^{x}$ is about $0.1 \mathrm{dyn} \mathrm{\textrm {cm } ^ { - 2 }}$ on the equator in the region of 58 to $62^{\circ} \mathrm{E}$. In the first case the equatorial response was very small with the subsurface maximum in $u$ being 1.3 $\mathrm{cm} \mathrm{s}^{-1}$, whereas in the second case the maximum was $4.8 \mathrm{~cm} \mathrm{~s}^{-1}$ which is about one-quarter of the value obtained using Hellerman and Rosenstein's data (see Fig. 7). The main response to this type of off-equatorial forcing was in the surface-height field.

Second, we tested the model using an idealized wind stress of the form $0.25 \exp \left[-(y / L)^{2}\right]$ dyn $\mathrm{cm}^{-2}$, applied across the whole basin for various values of $L$. We found that, provided $L$ was larger than about $500 \mathrm{~km}$, the results on the equator were insensitive to the precise value of $L$. For example, the magnitude of the second mode focus maximum of $u$ in the center of the ocean varied between $44.0 \mathrm{~cm} \mathrm{~s}^{-1}$ when $L=500 \mathrm{~km}$ and $49.3 \mathrm{~cm} \mathrm{~s}^{-1}$ when $L=1500 \mathrm{~km}$. In conclusion, the model results on the equator are insensitive to the forcing polewards of approximately $4^{\circ} \mathrm{N}$ and $4^{\circ} \mathrm{S}$.

\section{d. $\tau^{x}$ as a function of $x$}

The solution on the equator is very sensitive to both the magnitude and phase of the forcing $\tau^{x}$ along the equator. This is most easily demonstrated by solutions when $\tau^{x}$ has the form $0.25 \exp \left[-(y / L)^{2}\right]$ dyn $\mathrm{cm}^{-2}$, where $L=750 \mathrm{~km}$, but acts over different longitude ranges. We ran three cases which are for stress over the whole ocean basin, the western half and the eastern half of the basin. Properties of the phases of these runs at the array are also listed in Table 4. It shows that the model strongly distinguishes between forcing in the west and east because the whole pattern of forcing and reflections changes. Forcing over the western half of the basin does not produce upward vertical phase propagation at all array longitudes nor westward propagation at all points at 500 and $750 \mathrm{~m}$, whereas forcing in the eastern half has both these properties. The amplitude of the subsurface maximum in $u$ near the center of the ocean is also very sensitive to the zonal extent of the forcing. The maxima for the three cases listed in Table 4 are $47.3,19.6$ and $28.5 \mathrm{~cm} \mathrm{~s}^{-1}$, respectively.

\section{Model simplifications}

\section{a. Only the second vertical mode}

If only the second vertical mode is retained in the solution then, obviously, the horizontal patterns will be a good approximation at any depth where the second mode dominates, between 600 and $850 \mathrm{~m}$ for example, but will be very poor near $200 \mathrm{~m}$ where the second 
mode is small. Fig. 11 is a plot of the amplitude and phase of the simpler solution along the equator between $150 \mathrm{~m}$ and $2.5 \mathrm{~km}$. Comparison with Fig. 7 shows that the amplitude is quite good, but the phase is completely wrong because a single vertical mode cannot show vertical propagation. The observed phases also cannot be simulated well by this simplified solution. Thus, this is not a good overall approximation to the full solution, even though this mode has the largest projection coefficient in that solution.

\section{b. Only the Kelvin and first Rossby waves}

In this simplification only the Kelvin and first Rossby waves are retained in all 14 vertical modes of the model. This solution can only work well very near the equator where these two gravest waves are dominant. Fig. 12 shows the amplitude and phase of $u$ along the equator between $150 \mathrm{~m}$ and $2.5 \mathrm{~km}$ for this simpler solution, and should again be compared to Fig. 7. Comparison shows that the upward and westward phase propagation of the observations and the standard case over the array is captured quite well by this simplified solution. However, the magnitude is underestimated; the subsurface maximum in $u$ is only 10.5 rather than 18.1 $\mathrm{cm} \mathrm{s}^{-1}$. The explanation for this is that many Rossby waves are needed for a good representation of this second-mode focus, and here there is only one rather than the $\mathbf{3 0}$ of the full solution. Thus, this simplified solution only works reasonably well on the equator, and cannot be good away from it.

\section{c. Non-reflecting boundaries}

Non-reflecting, or the absence of, lateral boundaries can easily be simulated in the model. This is achieved

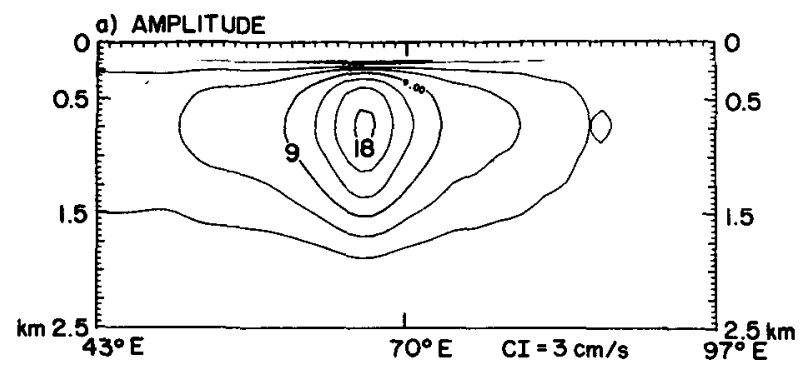

b) PHASE

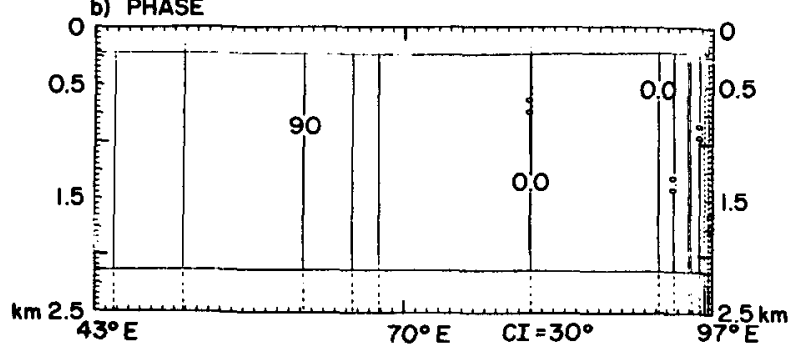

FIG. 11. Vertical section of a) amplitude and b) phase of $u$ along the equator between $150 \mathrm{~m}$ and $2.5 \mathrm{~km}$ when only the second vertical mode is retained. The amplitude unit is $\mathrm{cm} \mathrm{s}^{-1}$.
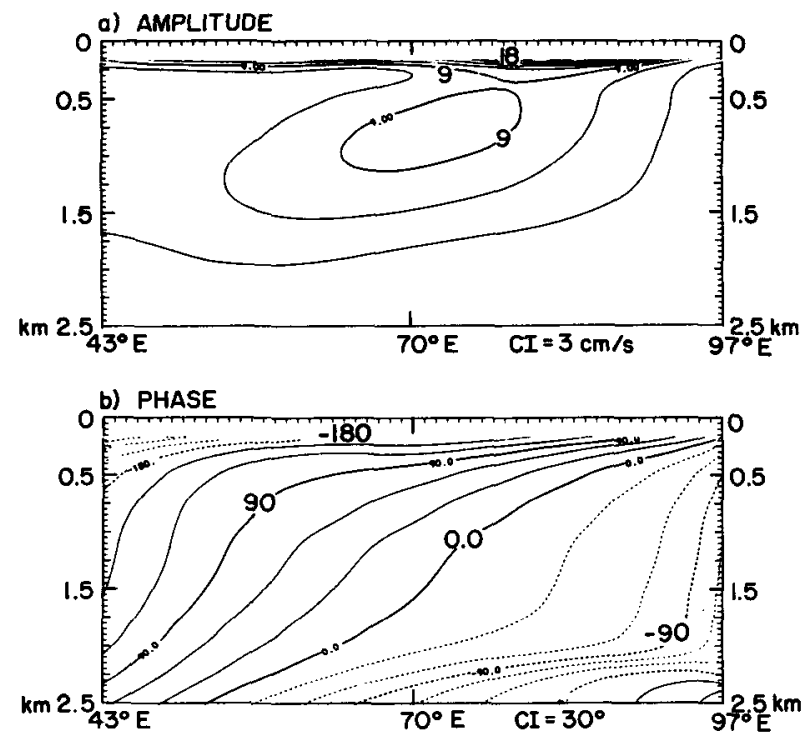

FIG. 12. Vertical section of a) amplitude and b) phase of $u$ along the equator between $150 \mathrm{~m}$ and $2.5 \mathrm{~km}$ when only the Kelvin and first Rossby waves are retained. The amplitude unit is $\mathrm{cm} \mathrm{s}^{-1}$.

by setting $\rho_{n}$ equal to zero in Eqs. (A13) and (A19), and adding a Kelvin wave to (A13) such that $a_{k}$ is zero at the western boundary, $43^{\circ} \mathrm{E}$. Fig. 13 shows the resulting amplitude and phase of $u$ along the equator between $150 \mathrm{~m}$ and $2.5 \mathrm{~km}$. The most striking feature of the figure is that the amplitude is very small everywhere below $300 \mathrm{~m}$. The reason is that the gravest waves that have significant amplitude propagate vertically at the shallowest angles to the horizontal. The high Rossby waves can reach the bottom still under the forcing region, but these waves have very small
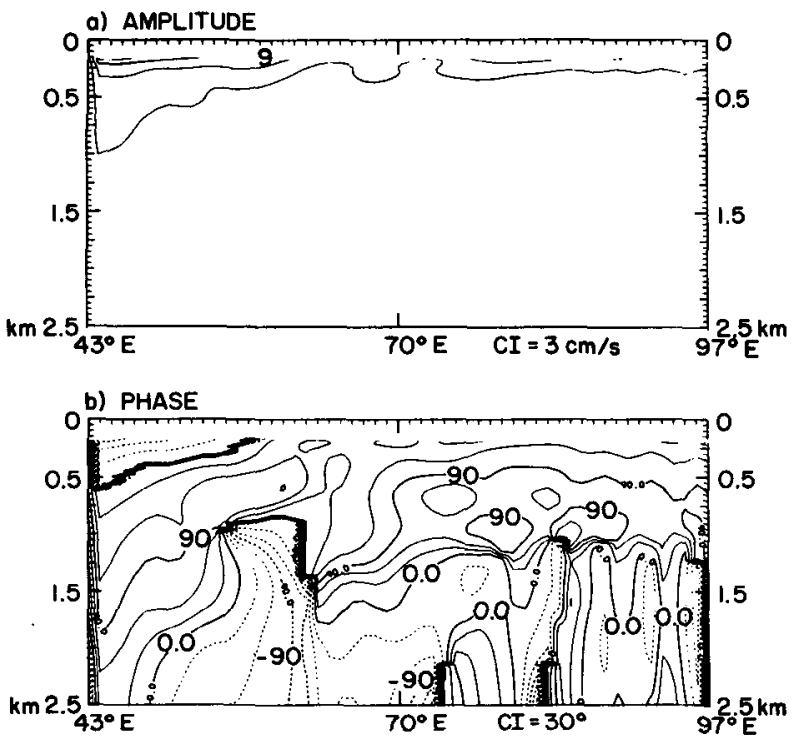

FIG. 13. Vertical section of a) amplitude and b) phase of $u$ along the equator between $150 \mathrm{~m}$ and $2.5 \mathrm{~km}$ when the lateral boundaries are non-reflecting. The amplitude unit is $\mathrm{cm} \mathrm{s}^{-1}$. 
amplitudes. The second mode focus in the center of the ocean is, of course, absent in this case because there are no boundary reflections. What Fig. 13 illustrates is that our full solution is very dependent upon the efficiency of wave reflection from the lateral boundaries, which we have assumed occurs perfectly.

In our vertically finite model, very little energy returns to the surface after reflection off the bottom when the friction is strong. Thus, the results of this subsection would be little different if we assumed a semi-infinite domain, as did Wunsch (1977). The important differences between our full solution and his are the inclusion of lateral boundaries and the spatially complicated wind-stress forcing. As we have seen, the simplified solution without reflections due to lateral boundaries is very different from the full solution and simulates the observations poorly.

\section{d. Vertically propagating waves}

The previous paragraph raises the question of the relation between our solution and one expressed in terms of vertically propagating waves. In general, there are two commonly used procedures for solving forced problems of the kind considered in this work (see Philander, 1978). In the one employed here, the vertically standing modes of the ocean are found first, and the horizontal structure of each mode is then calculated, before finally summing over the vertical modes. The second procedure is used for the atmosphere, where the absence of an upper lid means that there isn't a complete set of vertically standing free modes. One first solves for the horizontal modes, then calculates the vertical propagation corresponding to each, before finally summing over all the horizontal modes. Either procedure can be used to solve the oceanic problem, and they yield the same answer. One may choose between them on the basis of convenience, or because one or the other approach presents the result in a physically more revealing form. All other things being equal, the standing-mode approach is easier to compute than the vertically propagating one. This is not the case if the total response can be represented as just a few vertically propagating waves; for example, if boundaries are unimportant and the forcing spectrum has only a single zonal wavenumber, as by Wunsch (1977).

Visual inspection of our solutions (see Fig. 7) shows how hard it would be to characterize the response in terms of vertically propagating rays. Such rays are certainly present in our figures; the difficulty is that they are ubiquitous: rays emanate from every point of the surface and sidewalls. In this realistic problem a description in terms of rays is no more revealing than one in terms of standing modes, and perhaps less so: we are able to characterize many features solely in terms of the second baroclinic mode. In the present problem, boundaries are important and the wavenum- ber spectrum of the forcing is quite rich, so that a description in terms of a few vertically propagating waves is not possible.

\section{Conclusions and discussion}

Our main conclusion is that although the physics in the rnodel is very simple, namely a linear ocean forced at the surface at a single frequency, yet it works quite well in simulating the observations of Luyten and Roemmich (1982). As discussed in Section 4, the model amplitudes are somewhat smaller than in the observations, but the phases reproduce those of the observations well. Comparison of the solution with point measurements is sensitive to the precise locations, e.g., phase changes rapidly at $200 \mathrm{mn}$ (see Fig. 9). Also the model solution is the long term average, whereas the observations are one year's realization. Both Schott and Fernandez-Partagas (1981) and Wylie and Hinton (1982) agree that the very strong monsoon winds off Somalia did not start to blow until 10 June 1979, which is about two weeks later than average. However, from their data, it is very hard to tell whether the large semiannual oscillation in $\tau^{x}$ in the central equatorial Indian Ocean was also late in 1979. Given these caveats, the comparison is quite good.

Conclusions from Section 5 are that the results in the array area are only moderately sensitive to the depth of the mixed layer providing it is less than about $75 \mathrm{~m}$, but are sensitive to the exact form of friction when $r_{n} / \omega_{n}$ is small for the gravest modes. However, other features of the solution are very sensitive to friction. Another important conclusion is that the form of the wind stress polewards of about $4^{\circ}$ has very little influence on the solution at the equator. However, as is to be expected, the solution at the equator is very sensitive to the form of $\tau^{x}$ along the equator.

Conclusions from Section 6 are that simplified solutions having just the second vertical mode, or nonreflecting lateral boundaries do not approximate the full solution, nor simulate the observations, very well. The simplified solution retaining just the Kelvin and first Rossby waves works reasonably well on the equator, and hence in simulating the observations, but cannot be good away from it. The final conclusion is that in this realistic problem, where the lateral boundaries are important and the forcing has a fairly rich wavenumber spectrum, a description in terms of a few vertically propagating waves is not possible.

Finally, we discuss some physical processes omitted from the model. We are aware that the surface layer dynamics are not linear, and that nonlinearities in the upper ocean alter the solution below. Cane (1980) has shown that nonlinear effects, notably the downward advection of eastward momentum, tend to concentrate momentum at the equator and inject it at depths below the mixed layer. We think that neglect of such nonlinearities is the greatest flaw in our study, but a fully 
nonlinear multi-layer numerical model would be needed to take proper account of them. Another assumption to which the model solution is very sensitive is the reflection properties of the long propagating waves at the coasts. We have assumed that the incoming mass to the boundaries is perfectly reflected by the Kelvin and Rossby waves. Non-reflecting lateral boundaries, as discussed in Section 6, alter the solution profoundly, and the data comparison is much better when they are retained. It might be improved using some assumption about less than perfect reflection at the coasts. We have also assumed that the African and Sumatran coastlines are oriented north to south. The wave reflections at these coasts would also be changed if their true orientations could be included. Another factor influencing the wave reflections near Africa could well be the Somali Current, which is a direct response to the winds along the coast. This strong current doubtless alters the details of the reflection process, although it seems unlikely it would alter the essential integral boundary condition (A11) that determines the Kelvin wave amplitude. A more significant effect is probably the generation of Kelvin waves by the current itself. These last physical processes are beyond the scope of the present model.

Acknowledgments. This work was supported by the National Science Foundation: for the first two authors by its sponsorship of NCAR and for the last author by Grant OCE-7922046 to MIT.

\section{APPENDIX}

\section{The Model Solution}

The general solution of Eqs. (11)-(13) is given in Eq. (9) of Cane and Sarachik (1981). The long-time asymptotic part of the forced solution is that proportional to $\exp \left(i \omega_{n} t\right)$. The Fourier Transform (FT) of this forced solution is

$$
\begin{aligned}
& \mathrm{FT}\left[u_{n}, p_{n}\right]=P_{n} \exp \left(i \omega_{n} t\right)\left\{\bar{d}_{k}(k) \mathbf{K}(y) / i\left(k-\bar{\omega}_{n}\right)\right. \\
& \left.+\sum_{m=0}^{M(n)} i \bar{r}_{m}(k) \mathbf{R}_{m}(y)(2 m+1) /\left(k+(2 m+1) \bar{\omega}_{n}\right)\right\},
\end{aligned}
$$

where the projections $\bar{d}_{k}$ and $\bar{r}_{m}$ are defined by

$$
\begin{gathered}
\bar{d}_{k}=\mathrm{FT}\left[d_{k}=2^{-1 / 2} \int_{-\infty}^{\infty} \tau^{x} \Psi_{0} d y\right], \\
\bar{r}_{m}=\mathrm{FT}\left[r_{m}=\int_{-\infty}^{\infty}\left[\tau_{y}{ }^{x}-(2 m+1)^{-1} y \tau^{x}\right] \Psi_{m} d y\right],
\end{gathered}
$$

and $\Psi_{m}$ are the Hermite functions given by

$$
\Psi_{m}=H_{m}(y) \exp \left(-y^{2} / 2\right) /\left(\pi^{1 / 2} 2^{m} m !\right)^{1 / 2},
$$

where $H_{m}$ is the Hermite polynomial of degree $m$. The vector functions $K$ and $\mathbf{R}_{m}$ are defined by

$$
\begin{gathered}
\mathbf{K}=2^{-1 / 2}\left[\Psi_{0}, \Psi_{0}\right], \\
\mathbf{R}_{m}=8^{-1 / 2}\left[(m+1)^{-1 / 2} \Psi_{m+1}-m^{-1 / 2} \Psi_{m-1},\right. \\
\left.(m+1)^{-1 / 2} \Psi_{m+1}+m^{-1 / 2} \Psi_{m-1}\right],
\end{gathered}
$$

and $M(n)$ is the number of long propagating Rossby waves for the $n$th vertical mode. Now it is easily shown that

$$
\frac{1}{i(k+b)}=\mathrm{FT}[\exp (i b x)]
$$

for any quantity $b$ that is independent of $k$. Thus the coefficients of $K$ and $\mathbf{R}_{m}$ inside the braces of Eq. (A1) can be written as the products

and

$$
\mathrm{FT}\left[d_{k}\right] \mathrm{FT}\left[\exp \left(-i \bar{\omega}_{n} x\right)\right]
$$

$$
\mathrm{FT}\left[-r_{m}(2 m+1)\right] \mathrm{FT}\left[\exp \left(i(2 m+1) \bar{\omega}_{n} x\right)\right],
$$

respectively. These coefficients can be evaluated using the convolution theorem for Fourier transforms, which is

\section{$\mathrm{FT}\left[f_{1}\right] \mathrm{FT}\left[f_{2}\right]$}

$$
=\mathrm{FT}\left[\int_{-\infty}^{\infty} f_{1}\left(x^{1}\right) \mathrm{f}_{2}\left(x-x^{1}\right) d x^{1}\right],
$$

and the fact that $d_{k}$ and $r_{m}$ are zero outside the basin, i.e., for $x<0$ and $x>X_{E} . X_{E}$ is taken to be $54^{\circ}$ from $43^{\circ} \mathrm{E}$ to $97^{\circ} \mathrm{E}$.

The short Rossby waves at the western boundary, which are not included in the solution, merely redistribute mass along that boundary. Thus the correct boundary conditions are

$$
\left.\begin{array}{rll}
\int_{-\infty}^{\infty} u d y=0 & \text { at } & x=0 \\
u=0 & \text { at } & x=X_{E}
\end{array}\right\} .
$$

We define

$$
\phi=\bar{\omega}_{n} X_{E} \text { and } \xi=\left(x-X_{E}\right) / X_{E} .
$$

Then the solution to Eqs. (11)-(13) satisfying (A11) is (see Cane and Sarachik, 1981)

$$
\begin{aligned}
{\left[u_{n}, p_{n}\right]=} & P_{n}\left(i \bar{\omega}_{n}\right)^{-1} \exp \left(i \omega_{n} t\right)\left\{a_{k}(x) \mathbf{K}(y)\right. \\
& +\sum_{m=0}^{M(n)} a_{m}(x) \mathbf{R}_{m}(y)+\rho_{n}[\mathbf{K} \exp (-i \phi \xi) \\
& \left.\left.+\sum_{m=0}^{M(n)} 2 \alpha_{m} \mathbf{R}_{m} \exp (i \phi \xi(2 m+1))\right]\right\}
\end{aligned}
$$

Here

$$
\begin{array}{r}
a_{k}(x)=-\int_{\xi}^{0} d_{k}\left(\xi^{\prime}\right) \exp \left[i \phi\left(\xi^{\prime}-\xi\right)\right] i \phi d \xi^{\prime}, \\
a_{m}(x)=\int_{\xi}^{0} r_{m}\left(\xi^{\prime}\right) \exp \left[-i(2 m+1) \phi\left(\xi^{\prime}-\xi\right)\right] \\
\times(2 m+1) i \phi d \xi^{\prime},
\end{array}
$$


and $\alpha_{m}$ and $\rho_{n}$ are defined by

$$
\begin{gathered}
\alpha_{2 m+1}=\frac{[(2 m+1) !]^{1 / 2}}{2^{m} m !}, \\
\alpha_{m}=0, \quad m \text { even, } \\
\rho_{n}=\frac{\left\{\sum_{m=0}^{M(n)}[2 m(m+1)]^{-1} \alpha_{m} a_{m}-a_{k}\right\}(\xi=-1)}{\exp (i \phi)[1-\exp (-2 i \phi) S(\exp (2 i \phi))]},
\end{gathered}
$$

where

$S[\exp (2 i \phi)]$

$$
=\sum_{m=0}^{M(n)}[m(m+1)]^{-1} \alpha_{m}^{2} \exp [-2 i m \phi] .
$$

The corresponding solution for $v_{n}$ can be calculated similarly, and is

$$
\begin{array}{r}
v_{n}=P_{n} \exp \left(i \omega_{n} t\right)\left\{\sum _ { m = 0 } ^ { M ( n ) } \left[a_{m}(x)-\int_{-\infty}^{\infty} \tau_{y}{ }^{x} \Psi_{m} d y\right.\right. \\
\left.\left.+2 \rho_{n} \alpha_{m} \exp (i \phi \xi(2 m+1))\right] \Psi_{m}(y)\right\} .
\end{array}
$$

The total solution is

$$
[u, v, p]=\sum_{n=1}^{\bar{n}} F_{n}\left[u_{n}, v_{n}, p_{n}\right]
$$

where $\bar{n}$ is the number of vertical modes retained in the calculation.

\section{REFERENCES}

Bruce, J. G., 1981: Variations in the thermal structure and wind field occurring in the western Indian Ocean during the monsoons. Tech. Rep. TR-272, Naval Oceanographic Office, $193 \mathrm{pp}$.

Cane, M. A., 1980: On the dynamics of equatorial currents, with application to the Indian Ocean. Deep-Sea Res., 27, 525-544.
- , and D. W. Moore, 1981: A note on low-frequency equatorial basin modes. J. Phys. Oceanogr., 11, 1578-1584.

ocean to periodic forcing. J. Mar. Res.. 39, 651-693.

Hellerman, S., and M. Rosenstein, 1983: Normal monthly wind stress over the world ocean with error estimates. J. Phys. Oceanogr., 13, 1093-1104.

Lighthill, M. J., 1969: Dynamic response of the Indian Ocean to onset of the southwest monsoon. Phil. Trans. Roy. Soc. London, A265, 45-92.

Luyten, J. R., and D. H. Roemmich, 1982: Equatorial currents at semi-annual period in the Indian Ocean. J. Phys. Oceanogr., $12,406-413$.

McCreary, J. P., 1981a: A linear stratified ocean model of the equatorial undercurrent. Phil. Trans. Roy. Soc. London, A298, 603635

- 1981b: Modeling deep equatorial jets. Recent Progress in Equatorial Oceanography, J. P. McCreary, D. W. Moore and J. Witte, Eds., Nova/MIT Press, 373-380.

McPhaden, M. J., 1982: Variability in the central equatorial Indian Ocean. Part 1: Ocean dynamics. J. Mar. Res., 40, 157-176.

Moore, D. W., and S. G. H. Philander, 1977: Modeling of the tropical ocean circulation. The Sea, Vol. 6, Interscience, 319-361.

O'Neill, K., 1982: Observations of vertically propagating equatoriallytrapped waves in the deep western Indian Ocean. Ph.D. dissertation, Johns Hopkins University, 162 pp. [Also WHOI Tech. Rep. 82-11.]

Philander, S. G. H., 1978: Forced oceanic waves. Rev. Geophys. Space Phys., 16, 15-46.

to periodic forcing. J. Geophys. Res., 86, 1903-1916.

Schopf, P. S., D. L. T. Anderson and R. Smith, 1981: Beta dispersion of low-frequency Rossby waves. Dyn. Atmos. Oceans, 5, 187214.

Schott, F., and J. Fernandez-Partagas, 1981: The onset of the summer monsoon during the FGGE 1979 experiment off the east African coast: A comparison of wind data collected by different means. J. Geophys. Res., 86, 4173-4180.

Wunsch, C., 1977: Response of an equatorial ocean to a periodic monsoon. J. Phys. Oceanogr., 7, 497-511.

Wylie, D. P., and B. B. Hinton, 1982: The wind stress patterns over the Indian Ocean during the summer monsoon of 1979. $J$. Phys. Oceanogr., 12, 186-199.

Wyrtki, K., 1973: An equatorial jet in the Indian Ocean. Science, 181, 262-264. 